\title{
CON-VIVENDO COM A SOROPOSITIVIDADE HIVIAIDS: DO CONCEITO AOS PRECONCEITOS
}

\author{
LIVING WITH POSITIVE SERUM FOR HIVIAIDS: FROM CONCEPT TO \\ PRECONCEPTIONS \\ CON-VIVIENDO CON LA SOROPOSITIVIDAD HIVISIDA: DEL CONCEPTO \\ ALPREJUICIO
}

Inácia Satiro Xavier de Françat

\begin{abstract}
RESUMO: Estudo interacionista objetivando identificar as reaçöes e sentimentos do enfermeiro/ cliente em relação a soropositividade HIVIAIDS. Emergiram dos discursos dos enfermeiros os significados: ter dificuldade de interação pelo medo do contágio e morte; tratar o cliente como nãopessoa; atuar como "informado". Dos discursos das pessoas soropositivas extrairam-se os significados: ser não-igual; aderir a vitimização/auto-exclusão; usar a manipulaçăo da impressão; e ser desviante normal. Estas significaçōes subsidiaram a reflexão acerca do seu conteúdo à luz da obra Estigma: notas sobre a manipulação da identidade deteriorada, de Erwing Goffman(1988) e da Resolução COFEn -160/93. A compreensão do fenômeno sinaliza para práticas defensivas $\mathrm{e}$ excludentes, de ambas as partes, fundamentadas no temor da morte. Os resultados indicam necessidade de treinamento e oficinas de sensibilização dos profissionais de modo a capacitá-los para um cuidar holistico e humanitário que favoreça a (re)socialização do soropositivo.
\end{abstract}

PALAVRAS-CHAVE: estigma do portador HIV, enfermagem e AIDS

\section{INTRODUZINDO A TEMÁTICA}

Era o ano de 1980 quando o mundo estremeceu ante o conhecimento da Sindrome da Imunodeficiência Adquirida - SIDA, uma doença tida como incurável e de sobrevida curta. Em virtude destas caracteristicas, tal patologia suscitou/suscita o temor do contágio como afetou/ afeta a psique da humanidade devido ao medo e a insegurança que acometem as populaçōes ante a possibilidade da finitude existencial.

Como a AIDS foi, primariamente, detectada entre homossexuais masculinos, năo faltaram cogitaçōes religiosas, supersticiosas e simplistas correlacionando aquelas pessoas infectadas com culpa e castigo divino, dado ao comportamento sexual diferenciado.

Posteriormente, a AIDS foi diagnosticada no continente africano e, desta vez, acometendo homens e mulheres heterossexuais. $O$ fato levou a comunidade cientifica a concluir que 0 agente causal da sindrome era um microrganismo transmitido por via sexual, independente de uma prática bi, homo ou heterossexual.

Em 1983, na França, estudos cientificos realizados por Gallo (1987), comprovaram que a AIDS é conseqüência do contágio pelo virus da Imunodeficiência Humana-HIV. Trata-se de um retrovirus que ataca seletivamente os linfócitos $T$, acarretando depleção quantitativa e progressiva das células T4 e, segundo Gallo (1987), Laurence (1985) e Urba e Longo (1985), a infecção destas células contribui para o desenvolvimento de anomalias na funçăo das células $B, T 8, N K$

\footnotetext{
${ }^{1}$ Enfermeira. Professora visitante da Universidade Estadual da Paraiba. Doutoranda em Enfermagem da UFC.
} 
e nos monócitos/macrófagos. Sabe-se, hoje, que existem dois tipos de sorotipos: o HIV -1 e o HIV -2, sendo que o principal agente etiológico da sindrome é o HIV -1.

Com a desmistificação da causa desta doença, os cientistas foram mais além com suas investigações e constataram a ocorrência da SIDA entre pessoas hemofilicas, transfundidas, em usuários de drogas e em crianças filhas de mães infectadas.

De acordo com o Programa Global da AIDS (GPAOMS) publicado pelo Ministério da Saúde (BRASIL, 1999), desde o início da epidemia até dezembro de 1994 já são, em todo o mundo, mais de 18 milhões de infectados e destes, $62 \%$ se contaminaram por contato heterossexual. Para o ano 2000 estima-se que haverá uma prevalência de 30 a 40 milhões de infectados, donde 75 à $80 \%$ devido a transmissão heterossexual, numa proporção de $50 \%$ para ambos os sexos. Ainda segundo este órgăo, o Brasil figura como o quarto pais do mundo em maior número de casos notificados, com um total de óbitos, até 1997, de 101.374, sendo que 26.059 eram do sexo feminino e 75.315 do sexo masculino.

Atualmente, os cientistas asseguram que a transmissão do agente infeccioso está relacionada com a via hematológica e, portanto, as vitimas da infecção são aquelas pessoas que adotam "comportamento de risco" praticando sexo inseguro (sem camisinha); receberam sangue ou seus derivados contaminados; compartilham drogas injetáveis fazendo uso da mesma seringa e agulha, crianças que adquiriram a doença por via perinatal ou, ainda, profissionais que se contaminaram, acidentalmente, no transcurso de alguma prática assistencial que envolveu o contato entre uma soluçăo de continuidade daquele com o sangue do soropositivo.

Apesar da equipe de saúde possuir, por formação, maior grau de esclarecimento acerca desta sindrome e seus mecanismos de transmissão ainda se percebem, no âmbito institucional, represálias de alguns profissionais em relaçăo aqueles clientes soropositivos para HIVIAIDS. Tal percepção motivou o presente estudo que objetivou identificar as reaçöes e sentimentos dos enfermeiros com relação à atuação junto a esta clientela e quais as implicações deontológicas explicitadas em suas atitudes e investigar as dificuldades psico-sociais vivenciadas pelas pessoas soropositivas para HIVIAIDS.

\section{ILUMINANDO A ROTA DO ESTUDO}

Trata-se de um estudo descritivo, com abordagem qualitativa, fundamentado na obra Estigma: sotas sobre a manipulaçäo da identidade deteriorada, de Erwing Goffman (1988), uma perspectiva teórica oriunda do campo sociológico, e na Resolução COFEN-160/93.

Elegemos como amostra dois grupos distintos: Grupo I - composto por 10 enfermeiros de um Hospital Universitário do Estado da Paraiba, e o Grupo II - 5 pessoas soropositivas para - HIVIAIDS que assumem, de público, a sua condição. Os grupos foram esclarecidos acerca dos objetivos do estudo, do caráter sigiloso e declinante das suas participações na pesquisa e Ihes foi solicitado permissão para o uso de gravador durante as entrevistas. Utilizamos uma entrevista semi-estruturada com uma única questão norteadora para cada um dos grupos. Ao Grupo I, fizemos a pergunta: Como você se sente assistindo a uma pessoa soropositiva para HIVIAIDS? Ao Grupo II, lançamos a interrogação: Como você está con-vivendo com - HIVIAIDS? Todos os sujeitos receberam um pseudônimo e todas as falas foram transcritas e expostas a repetidas leituras de modo a apreendermos os símbolos significantes de cada discurso em separado. Desvelado o seu simbolismo, antevemos o alcance dos objetivos traçados para a investigação.

\section{DESVENDANDO OS MITOS}

O estigma constitui-se uma marca ou impressão que sinaliza para um grupo a relação entre atributos e estereotipo de um determinado individuo, "avisando" aos demais que esta 
pessoa "marcada" não deve ser aceita plenamente. Portar um estigma implica em possuir uma característica não previsivel pela sociedade. Dai a crença de que "alguém com um estigma não seja completamente humano. Com base nisso, fazemos vários tipos de discriminações, através das quais, efetivamente, e muitas vezes sem pensar, reduzimos suas chances de vida" (Goffman, 1988). Tal ideologia busca explicar a inferioridade do outro e mostrar o perigo que representa para justificar a sua marginalizaçăo.

Por sua vez a pessoa discriminada tem as mesmas crenças dos demais sobre identidade e por isso acredita que "merece um destino agradável e uma oportunidade legitima" (Goffman, 1988). Ser tratada de modo diferente gera um conflito entre os seus sentimentos acerca daquilo que de fato é e a sensaçăo de ser uma pessoa igual às outras. Nesta condição, e no caso deste estudo, o soropositivo se obriga a vivenciar o papel de pessoa desacreditada, ou seja: alguém que se torna alijado socialmente por "apresentar às outras pessoas um eu precário, sujeito ao insulto e ao descrédito" (Goffman, 1999). Assim, o pólo gravitacional da qualidade de vida da pessoa estigmatizada denomina-se "aceitação". Esta atitude comportamental se impõe uma vez que o sujeito descobre que aqueles com quem se relaciona não o respeitam nem 0 consideram, apesar de possuir em sua identidade atributos não contaminados que garantiriam esta condescendência.

Uma conduta social discriminante e preconceituosa pode determinar o auto-isolamento da pessoa desacreditada, fazendo com que se torne "desconfiada, deprimida, hostil, ansiosa e confusa " (Goffman, 1988), levando-a a conjeturar aquilo que os outros pensam a seu respeito a partir da leitura dos significados não intencionais nas ações de outrem. A consequêencia natural deste tipo de interação é a inquietação e a agressividade entre os atores que dela participam. Os enfermeiros entrevistados expressaram ter dificuldade de interação pelo medo do contágio e morte, através das falas:

... é difícil trabalhar com esta clientela, mas a gente não pode recusar. Foi prá isso que eu estudei... tenho muito medo, por isso reforço a auto-proteção... Júlio

... não posso me omitir, mas tenho medo... medo de me contaminar, de morrer. Não nego que se pudesse, não cuidava desse tipo de cliente. Roberta

... cuidar, eu cuido, mas tenho receio. Não é como cuidar de outro doente sabe? Tem sempre o medo da doença, da morte... Morgana

...não concordo em trabalhar neste tipo de enfermaria. A chefe até me escalou uma vez mas troquei com uma colega. Tenho muito medo dessa doença. Já pensou se pego essa doença? Penso nos meus filhos... Paula

... dou assistência com muito medo porque é uma doença contagiosa e incurável... é dificil controlar o medo de pegar a doença... Mirtes

Quando uma epidemia se difunde rapidamente, não importa a via de transmissão, origina práticas de distanciamento e/ou exclusão dos doentes. Goffman (1988) nos explica que os ambientes sociais estipulam as categorias de pessoas que neles podem ser encontradas e esta rotina possibilita o relacionamento com outras pessoas, sem atenção ou reflexão particular. Quando um estranho adentra em nosso ambiente logo perscrutamos sua categoria e os seus atributos; a partir dai as preconcepções acerca deste individuo transformam-se em expectativas normativas que sujeitam-se a exigências rigorosas. Deste modo a pessoa em foco deixa de ser considerada um ser comum e total para reduzir-se a alguém estragado e diminuto, o que determina a sua exclusão.

Diante desta ideologia consideramos oportuno afirmar que, segundo o Ministério da Saúde, a possibilidade de se contrair o HIV no ambiente de trabalho via exposição a sangue é de $0,3 \%$ após exposição percutânea, e de $0,09 \%$ em exposição mucocutânea. Caso a pele integra se exponha ao sangue infectado pelo HIV, o risco de contágio ainda é menor do que nas exposições 
mucocutâneas. Ainda, segundo o Ministério da Saúde, pesquisa com caso-controle em que se fez uso profilático com o AZT demonstrou uma redução em $81 \%$ do risco de soro-conversão após exposição ocupacional. Outrossim, há que se ter em mente que só são notificados ao Ministério da Saúde aqueles clientes soro positivos sintomáticos ou seja: que apresentam evidência laboratorial de infecção pelo HIV através de reação sorológica positiva em teste para pesquisa de anticorpos anti-HIV (ELISA) e/ou na presença de um teste repetidamente positivo para antígeno e/ou cultura positiva e/ou por PCR positivo. Além deste critério, para efeito de notificação, considera-se o conjunto de sinais e sintomas/doença que somem pelo menos 10 pontos, segundo o critério OPAS/Caracas, e/ou que a pessoa porte pelo menos uma doença oportunista para AIDS, a exemplo de Pneumonia por Pneumocystis carinii, toxoplasmose cerebral, herpes simples muco-cutâneo de duração > 1 mês, retinite por citomegalovirus e candidiase do esôfago (BRASIL, 1999).

A considerar estes critérios, subtende-se que aquelas pessoas soropositivas, mas assintomáticas, são "portadoras sadias" com potencial para contaminar outras pessoas e invalidam completamente o temor direcionado, especificamente, àqueles clientes diagnosticados como portadores deste mal. Os clientes, sintomáticos ou não para o HIVIAIDS, exporão ao risco de contaminação aqueles enfermeiros que não fizerem uso adequado de EPI. Deste modo, o ter conhecimento do diagnóstico clínico do cliente não justifica o uso de retaliaçōes ou postergações; e deixar de assisti-lo corresponde a afrontar a Resolução COFEn - 160/93, no seu art. $3^{\circ}$ : "O profissional de enfermagem respeita a vida, a dignidade e os direitos da pessoa humana, em todo o seu ciclo vital, sem discriminação de qualquer natureza."

Conforme Goffman (1988) uma das possibilidades comportamentais do ator social, ao interagir com um desconhecido estigmatizado, é tratá-lo como se este fosse melhor do que imagina que seja ou pior do que acha que de fato o outro é. Esta possibilidade poderá acarretar condutas discriminatórias e/ou preconceituosas que dispensarão ao outro o tratamento de "não pessoa", um tipo de personagem descrito como sendo alguém que participa de uma interação mas no entanto, é ignorado pelos demais. São exemplos de como tratar o cliente como nãopessoa os seguintes relatos:

...eu não falo nada prá ele... procuro esquecer o seu problema e finjo que não sei de nada...Glória

....acho que não compete à enfermagem falar alguma coisa prá ele... é um assunto delicado. Gorete

O cliente institucionalizado coloca nas mãos da equipe de saúde as suas esperanças de cura e de atendimento às suas necessidades básicas. Entre as necessidades afetadas de um cliente grave destacam-se aquelas de cunho psíquico que requerem atenção e pronto atendimento profissional.

Ao ignorar esta peculiaridade o enfermeiro está favorecendo a ocorrência da iatrogenia psicológica, visto que a sua interação com o cliente será marcada pela inquietação e/ou agressividade, sinalizadora das admoestaçōes, veladas ou não, sofridas pelo cliente, além do que esta conduta profissional denota inobservância do Art. 16 da Resolução-COFEn-160/93: "Assegurar ao cliente uma assistência de enfermagem livre de danos decorrentes de impericia, negligência ou imprudência."

Afora esta eventualidade, Goffman (1988) nos explica que uma pessoa com estigma pode defrontar-se com pessoas compassivas, que adotam a sua visão de mundo e estão dispostas a compartilhar consigo o sentimento de que ele é humano, "apesar das aparências e a despeito de suas próprias dúvidas." Trata-se dos seus pares - pessoas que também possuem um estigma e por isso săo solidárias com o companheiro de infortúnio. Além deste, há um outro grupo de pessoas compassivas, composto pelos "informados" - pessoas que, por oficio ou 
profissão, conhecem os percalços do cotidiano de quem carrega um estigma e participam da vida secreta desta pessoa, simpatizam com ela e gozam de aceitação e pertinência pelo grupo dos estigmatizados. São exemplos desse pressuposto:

...não consigo deixar de ter pena. Se o doente for muito jovem ai é que eu fico abalada. Não é fácil ver uma pessoa jovem com os dias contados e ter que atuar como se ela fosse viver por muito tempo... Faço o que posso mas fico triste por não poder fazer muito por este tipo de doente. Virna

... me sinto impotente diante desta doença. A gente fica em contato com eles sabendo que a nossa ajuda não resolve o problema e de repente a gente pensa... e se fosse comigo? Será que eu ia ter forças prá encarar essa barra? Infelizmente o que a gente faz é pouco para ajudar a estas criaturas. Julita

... tenho muita pena. Procuro ajudar o doente, fazer alguma coisa.. às vezes vou prá casa com um aperto no coração, de ver tanta doença ruim sem poder fazer nada. Mara

Apreende-se, da fala dos enfermeiros, a necessidade de fazer uso de estratégias para superar as dificuldades, tanto suas quanto do cliente a seus cuidados. Como mecanismo de superação do stress que, nesta situação, permeia a relação enfermeiro-cliente é comum o uso das técnicas de esclarecimento ao cliente acerca da continuidade do seu relacionamento sexual e da união civil, além do controle da informação e o encobrimento. Na obra Estigma, Goffman (1988)afirma que estas práticas são utilizadas no ambiente hospitalar, onde os profissionais de saúde mantém um diagnóstico em sigilo, revelando-o apenas para os seus pares, o cliente e os familiares mais próximos como modo de garantir a cooperação do cliente.

No caso do soropositivo, a Resolução 1.359/92 do Conselho Federal de Medicina proibe a revelação do seu segredo até para os familiares, persistindo a proibição de quebra de sigilo mesmo após o óbito do cliente. Cumpre reafirmar que esta conduta é um dos deveres profissionais expresso na Resolução COFEn - 160/93, no seu Art. 29:- "Manter segredo sobre fato sigiloso de que tenha conhecimento em razão de sua atividade profissional, exceto nos casos previstos em Lei." Primar por este segredo não só salvaguarda o cliente da solidificação do comportamento social em relação à sua pessoa, como lhe assegura a anulação da hipótese de morte social que Ihe negaria a liberdade de escolher o melhor para si e para o grupo dos familiares e amigos.

Interagindo socialmente, o soropositivo para HIVIAIDS desenvolve um sentimento de ambivalência relativo ao seu eu. Este fato, segundo Goffman (1988), dá margem aos ciclos de incorporação através dos quais o sujeito aceita as oportunidades de participação no grupo social ou rejeita-as após um periodo anterior de aceitação, motivado pela percepção de ser não igual como denota a fala:

... olhe moça é muito duro saber que a gente tem os dia contados... ficar sem emprego... As pessoas tem medo de pegar a doença com a gente... Como vou viver sem emprego? Hoje eu sou um zé ninguém... no começo foi muito duro. Não sabia como contar a minha familia. Foi muito sofrimento, né? Quando tive coragem, contei prá minha família e prá alguns amigos... foi uma loucura... Os parentes tentam me ajudar mas os amigos... sumiram... vou vivendo como Deus quer, até um dia... Mauro

Aprendemos com Goffmann (1988)que a pessoa ambivalente tende a estratificar seus pares de acordo com o grau de visibilidade e imposição do seu estigma. Neste estudo o personagem além de perceber-se como não-igual, apoia-se na crença de que a morte é uma ameaça constante que deve ser esperada e tolerada o quanto possivel.

De acordo com esse autor, o estigmatizado possui uma "sensibilidade especial às contingências da aceitação e da revelação, contingências às quais os normais serão menos 
sensiveis." Esta é uma premissa que possibilita ao não-igual questionar a desaprovação semioculta com que é tratado pelos demais e perscrutar nas atitudes dos informados algum ato falho que ateste a inverdade da sua aceitação. Este comportamento, quando não corrigido, o levarão a aderir a vitimização e/ou auto-exclusăo. O discurso a seguir é exemplo deste fenômeno:

... o pior é que você perde os amigos... você vira bicho... as pessoas fogem... você năo pode obrigar os outros a ficar do seu lado. Rita

Eis porque, segundo Goffman (1988), uma pessoa com estigma é vista como desconfiada, hostil, deprimida, ansiosa, confusa e insegura na presença de estranhos normais por desconhecer a maneira como o receberão o que levou o autor a aconselhar que o "bom ajustamento exige que o estigmatizado se aceite, alegre e inconscientemente, como igual aos normais enquanto, ao mesmo tempo, se retire voluntariamente daquelas situaçőes em que os normais considerariam dificil manter uma aceitação semelhante."

Numa tentativa de preservar a sua identidade a pessoa não-igual tende a assumir uma linha de conduta que favoreça as relações consigo mesma, de modo a assegurar a sua dignidade e o seu auto-respeito. Estas pessoas passam a usar a manipulação da impressão:

...tenho que ser forte... minha vida pode acabar a qualquer momento.... tenho que viver cada minuto como se fosse o último. Lúcio

....sei que a doença ainda näo tem cura mas se eu me cuidar direito... posso viver um pouco mais... Joăo

....Minha vida mudou muito depois que soube da doença. Vivo o tempo todo agoniado, com medo que os remédios não controle a doença. Uma enfermeira me disse que eu era um doente como outro qualquer... só preciso me cuidar e ter cuidado com os outros... só isso... André

Esta compreensão da realidade encontra apoio nas idéias de Goffman(1988) quando nos ensina que uma pessoa estigmatizada pode se definir como năo-diferente dos outros humanos apesar dele e daqueles que o cercam terem consciência da sua marginalização. Este raciocinio estimula ao ambivalente buscar uma filosofia de vida que forneça o sustentáculo da sua situação. Para alcançar tal intento esta pessoa, individualmente, ou ajudada por profissionais, elaborará um código em torno de questōes-padrão que regularãọ a sua carreira moral e facilitarăo o comportar-se como desviante normal:

...tenho que continuar procurando a melhor maneira de viver com essa doença. Lúcio

... a gente não pode desanimar. Precisa buscar apoio, caçar os direitos da gente. João

O código elaborado pelo desviante fornecerá um modelo desejável acerca das tomadas de decisão; de como aprender a lidar com situaçōes delicadas; qual o tipo de apoio que deve proporcionar aos seus iguais; quais os preconceitos que deve ignorar e os que precisa combater abertamente e o modo como deve encarar o seu atributo diferencial (Goffman, 1988). Ao participar da elaboraçăo deste código o enfermeiro deve ter em mente que ao garantir os direitos do cliente, familiares e amigos estará, também, salvaguardando a própria equipe de enfermagem. Assim năo há como fugir aos ditames da Resolução COFEn - 160/93, no seu art. 10: - "A enfermagem é uma profissão comprometida com a saúde do ser humano e da coletividade. Atua na promoção, proteçăo, recuperação da saúde e reabilitação das pessoas, respeitando os preceitos éticos e legais." Este modo de proceder implica em ajudar ao outro a ser uma pessoa bem sucedida, real e digna, o que reforça a sua autenticidade.

O caminho trilhado neste estudo nos revelou, através das falas dos respondentes, um 
movimento em favor da adaptação, quer seja no decorrer da interação enfermeiro-cliente soropositivo para HIVIAIDS, quer na interação destes clientes no campo das práticas sociais, e nos propiciou a compreensão do fenômeno em estudo levando-nos a aprender com Goffman (1988) que a sociedade exige, daquelas pessoas que carregam uma diferença, a adoçăo de uma conduta que não transpareça o peso da sua carga, aceitando naturalmente a si e aos outros, numa postura caracteristica de aceitação-fantasma, fornecendo a base para uma normalidade-fantasma.

\section{CONSIDERAÇÖES FINAIS}

Apesar de não ter sido possivel alcançar todas as faces do fenômeno "Con-vivendo com a soropositividade para o HIVIAIDS", este ensaio propiciou vislumbrar, junto aos enfermeiros, as dificuldades pessoais que podem interferir na dinâmica da interação com este tipo de cliente e antever que os entraves ao bom relacionamento profissional/cliente soropositivo tem suas raizes na co-relação da AIDS com a morte, desencadeando uma experiência de temor interiorizado que se traduz por possibilidade de contágio e morte.

Ao se colocar no lugar do outro o enfermeiro busca disfarçar e esconder seus sentimentos, racionalizando suas atitudes, assumindo um papel que o obriga ao uso da "máscara" de alguém frio e calculista. Esta representação sinaliza com a necessidade da equipe de saúde atuar à luz da multidisciplinaridade, primando por refletir e se "trabalhar", emocionalmente, como modo de oferecer a todo e qualquer cliente, não só o atendimento às suas necessidades biológicas, mas também às suas necessidades emocionais, em todas as vezes que estes clientes quiserem participar seus medos, angústias e esperanças.

Por sua vez, a interação dos soropositivos é marcada pela imperiosa necessidade de ocultação do diagnóstico como modo de preservar as relações sócio-trabalhistas. Revelar, alguém, este segredo implica em estigmatizá-los, obrigando-os a se adaptarem à condição de doentes, relegando os agravos emocionais que possam estar vivenciando, como manifestação de sua patologia.

A fragilidade desenhada na fala dos soropositivos traduz um pedido de socorro que requer sensibilidade e compromisso daquelas pessoas/profissionais envolvidos com o cuidar destes sujeitos, a fim de que possam investir no campo da interação cliente-equipe de saúde-familiasociedade, contribuindo de forma significativa para o sucesso da (re)socialização das pessoas com HIVIAIDS.

\footnotetext{
ABSTRACT:This is an interactive study which aimied at identifying the reactions and feelings of nurses/ clients in relation to positive serum for HIVIAIDS. From the nurses's narratives emerged the following meanings: to have difficulty in interacting due to the fear of infection and death; to treat the client as a non-person; to act as an "informed "professional. From the individuals with positive serum, the following meanings were extracted from their discourses: to be non-equal; to accept victimization/ self-exclusion; to impress by the use of manipulation and to be a normal deviant. This data served as groundwork for a reflection about their significances in light of the work Stigma: notes about the manipulation of the deteriorated identity, by Erwing Goffman and of the Resolution COFEn -160/93. The understanding of this phenomenon signals to defensive and excluding practices on both parts, based on the fear of death. The results indicate the need to carry out training and awareness workshops for health professionals in order to qualify them for a more holistic and humanitarian care that favors the (re)socialization of the positive serum individual.
}

KEYWORDS: stigma, preconceptions, nurses, positive serum, HIVIAIDS 
RESUMEN: Estudio interaccionista que objetiva identificar las reacciones y sentimientos del enfermero/ cliente respecto a la soropositividad HIVISIDA. Emergieron de los discursos de los enfermeros los significados: tener dificultad de interacción por el miedo al contagio y muerte; tratar al cliente como no-persona; actuar como ïnformado". De los discursos de las personas soropositivas se extrajeron los significados: ser no-igual; adherir a la victimización/autoexclusión; usar la manipulación de la impresión; y ser desviante normal. Estas significaciones subsidiaron la reflexión sobre su contenido a raiz de la obra Estiigma: notas sobre la manipulación de la identidad deteriorada, de Erwing Goffman y de la Resolución COFEn -160/93. La comprensión del fenómeno nos señala prácticas defensivas y excludentes, de ambas partes, fundamentadas en el temor a la muerte. Los resultados indican la necesidad de entrenamiento y oficinas de sensibilización de los profesionales de forma a capacitarlos para un cuidar holistico y humanitario que favorezca la (re)socialización del soropositivo.

PALABRAS CLAVE: estigma, enfermeria e SIDA, soropositividade HIVISIDA

\section{REFERÊNCIAS BIBLIOGRÁFICAS}

BRASIL, Ministério da Saúde, Secretaria de Politicas de Saúde, Coordenação Nacional de DST e Aids. Manual de orientação básica para equipe de enfermagem/Prevenção do HIV e assistência a pessoas portadoras do HIV e de AIDS. Brasilia, 1999. p. 5

GALLO, R. The AIDS virus.Scientific American, n. 256, v, 1, p.45-56, 1987.

GOFFMAN, E. Estigma: notas sobre a manipulação da identidade deteriorada. 4. ed. Rio de Janeiro: Guanabara Koogan, 1988. 158 p.

A representação do eu na vida cotidiana. Petrópolis; Vozes, 1999, 233p.

LAURENCE, J. The immune system in AIDS. Scientifics American, v. 6, n. 253, p. 84-9, 1985.

URBA, W; LONGO, D. Clinical Spectrum of human retroviral induced diseases. Cancer Research, 45 (supll) $4637-4643,1985$.

Recebido em janeiro de 2000

Aprovado em abril de 2001 